\title{
Eutrophication-like response to climate warming: an analysis of Lago Maggiore (N. Italy) zooplankton in contrasting years
}

\author{
Anna VISCONTI, Marina MANCA* and Riccardo DE BERNARDI \\ CNR Institute for the Study of Ecosystems, Largo Tonolli 52, 28922 Verbania, Italy. \\ *e-mail corresponding author:m.manca@ise.cnr.it
}

\begin{abstract}
Global mean surface temperatures are increasing. All ecosystems are likely to be affected and there is much interest at present in predicting the effects. In freshwater environments, we expect to observe, among other things, effects similar to those observed under eutrophication, such as increases in zooplankton population density and biomass as a result of enhanced population growth rates. Lago Maggiore underwent rapid eutrophication during the 60s and 70s, with a return to oligotrophy during the 80s and the 90s. Thus, it provides a case study to test the hypothesized eutrophication-like effects of recent climate warming. More specifically, we compare zooplankton biomass and density during the exceptionally warm years of the recent oligotrophic phase with values during the non-warm years of oligotrophy, and during years of the mesotrophic phase. This permits an analysis of zooplankton biomass and density with respect to temperature increase compared with the effects of eutrophication. Zooplankton population density and biomass sharply increased in 2003, the warmest year of the last century, as a result of Cladocera, particularly Daphnia, attaining values typical of the mesotrophic phase. These values were exceptional compared to typical values and were strongly different from those attained during cooler years since re-oligotrophication. Mean annual values of zooplankton density and biomass recorded in 2003 were fully comparable to typical values during the mesotrophic period. This observation confirms the hypothesis of an overall eutrophication-like effect of climate warming. Seasonal trends, characterized by an earlier start of population growth, are consistent with the effects of an increase in water temperature, as observed in laboratory experiments on the reproductive and growth strategies of Daphnia.
\end{abstract}

Key words: global warming, eutrophication, zooplankton, Daphnia

\section{INTRODUCTION}

Greenhouse gases are steadily warming the Earth. An increasing number of studies, using different approaches, have been made on a regional scale in an attempt to analyze the responses of different ecosystems to this warming trend, and to predict its future effects. Climate change can alter temperature regimes in freshwater ecosystems, and this variation inevitably affects the community dynamics of freshwater populations (Persaud \& Williamson 2005). In particular, the response of lakes to climate change deserves further investigation, as we are far from understanding the potential effects of global warming and climate change on the different components of lake biota (De Stasio et al. 1996).

Small planktonic crustaceans, particularly cladocerans, are highly sensitive to environmental change (Hall \& Burns 2002). Variations in the physical environment, particularly in water temperature, may affect the structure of their populations by modifying biological processes such as survival, growth and reproduction rates (Hall \& Burns 2002), as well as the structure and seasonal dynamics of planktonic communities.

So far, most studies on climate change have focused on remote, oligotrophic sites, characterized by harsh conditions and a relatively low anthropogenic impact.
The lakes are mostly small, with simple and short food webs that often lack top predators. Therefore, meteoclimatic signals are not overridden by trophic dynamics mechanisms.

The hypothesis behind this approach is that nutrient enrichment prevails over climatic forcing. However, we do not have enough evidence on trophy-climate interaction, and on the role of direct/trophy-mediated response to climate change to confirm this hypothesis. Furthermore, we do not know whether the impact of climate and of meteo-climatic events depends on lake trophy.

According to the literature, warming should have effects on aquatic ecosystems comparable to those of eutrophication (e.g., Schindler 2001). However, we need more evidence on the impact of warming on lakes under different trophic conditions. After eutrophication became evident in many lakes in the late $60 \mathrm{~s}$, restoration plans were implemented to return some of the lakes to their original trophic condition. In most cases, a resilience in the response to nutrient abatement was observed, and a full reversal to pre-eutrophication planktonic communities was not attained. If these systems are now subjected to a warming trend that is similar to eutrophication in its consequences but cannot be controlled through direct intervention as nutrient inputs could be, the results might be even more dramatic than those observed during nutrient enrichment. These 
Tab. 1. Basic characteristic of the Lago Maggiore ecosystem during warm and temperate years in the mesotrophic and oligotrophic periods. TP $=$ Total Phosphorus.

\begin{tabular}{lccccc}
\hline & \multicolumn{2}{c}{ During mesotrophy } & & \multicolumn{2}{c}{ During oligotrophy } \\
\cline { 2 - 3 } characteristic & warm & temperate & & warm & temperate \\
year & 1982 & & 2003 & 2001 \\
TP at spring mixing & \multicolumn{2}{c}{$22-23 \mu \mathrm{g} \mathrm{L}^{-1}$} & & & $10-11 \mu \mathrm{g} \mathrm{L}^{-1}$ \\
Total pelagic fish (profes. catch) & \multicolumn{2}{c}{$650 \mathrm{t} \mathrm{y}^{-1}$} & & $200 \mathrm{t} \mathrm{y}^{-1}$ \\
\hline
\end{tabular}

effects might also be entirely non-reversible, particularly for systems which are already highly productive.

To investigate the interaction between climate warming and trophy, long-term data covering both the eutrophication and re-oligotrophication phases of a lake can be extremely useful. They allow us to identify exceptional events which may have occurred in the same environment during different periods of trophy, and to use them as in situ quasi-experiments sensu Edmondson (1993).

Lago Maggiore (Italy) is a site where lake trophy and climate warming have been recorded over the last 60 years, through integrated monitoring of the lake and its watershed. This monitoring program allowed for a comparison of zooplankton population density and biomass during warm/temperate years of the meso- and of the oligotrophic phases. Based on pluri-annual data on zooplankton (de Bernardi et al. 1988, 1990; Manca et al. 1991; Manca \& Ruggiu 1998, Manca et al. 2007a), we identified two exceptionally warm years of the mesotrophic and recent oligotrophic phases (1982 and 2003 respectively). Then, each of them was compared to a temperate year (i.e., years that were not different from the adjacent four years of the period) of the same phase (Tab. 1). We hypothesized that in warm years we would observe (with respect to temperate years: $i$ ) an increase in total zooplankton biomass; ii) an increase in Cladocera abundance; iii) an increase in Daphnia population density.

\section{MATERIAL AND METHODS}

The exceptionally warm year 2003, during the oligotrophic period, and the warm year 1982, during the mesotrophic period, were compared to "normal" (temperate) years - 2001 and 1983, respectively - during the same trophic phases (Tab. 1). We analyzed biomass, mean annual population density and community structure of pelagic zooplankton, based on data collected by the zooplankton ecology and population dynamics research unit (1978-1999) and the Lago Maggiore monitoring program (funded by the Swiss-Italian Commission for the Protection of Lago Maggiore Waters: 1978-today) at CNR-ISE, Verbania, Italy. Samples from the upper $50 \mathrm{~m}$ water depth (the layer in which most zooplankton organisms live; de Bernardi 1974) were collected at a station (Ghiffa) representative of the pelagic zone. Sampling frequency was monthly over the autumn-winter period and weekly over spring and summer. Two Clarke-Bumpus plankton-samplers (nylon nets of $126 \mu \mathrm{m}$ and $76 \mu \mathrm{m}$ used in parallel) enabled us to collect both small (basically rotifers, immature stages of copepods and small Bosmina) and large zooplankton organisms from a boat moving at a low, constant cruise speed $\left(0.6 \mathrm{~m} \mathrm{~s}^{-1}\right)$, to allow the filtration of at least 1000 L of lake water (de Bernardi 1984). The resulting sinusoidal sampling trajectory allowed us to collect integrated samples, almost unbiased by the occurrence of plankton swarms (horizontal integration) and fully representative of pelagic crustacean zooplankton, which is mainly distributed within the upper $50 \mathrm{~m}$ of the water column. The samples were preserved in pure $(99 \%$ volume) ethanol. On each sampling date, water transparency (Secchi depth) and the water temperature vertical profile (thermistore thermometer) were recorded. The standing stock biomass (dry weight, $\mathrm{mg} \mathrm{m}^{-3}$ ) was calculated from individual body length measurements on each sample, by applying length/weight regression equations (McCauley 1984; Manca \& Comoli 2000). The egg ratio (E/Nad) of Daphnia is given by the number of eggs (E) divided by the number of adults (Nad). This ratio was used to detect changes in food availability (de Bernardi 1974; Lampert 1988; Manca et al. 2000), as enhanced food conditions result in increased allocation of energy and matter for egg production (Manca \& de Bernardi 1987).

We used non-parametric statistics (LSD, Least Statistical Difference; Statistica, ver. 6) to test the significance of differences in Daphnia population densities between periods with differing combinations of trophic state and warm versus temperate weather.

\section{RESULTS}

All monthly mean water temperatures recorded in 2003 were higher than those of the period 1963-2002 (Fig. 1A). The greatest differences were apparent in late summer, from July through September. Maximum values along the $50 \mathrm{~m}$ depth-profiles were also greater in 2003 than in 2001; the July and August values differed by fully $5{ }^{\circ} \mathrm{C}$ and $4{ }^{\circ} \mathrm{C}$, respectively (Fig. 1A). Furthermore, water warming started a few weeks earlier in 2003 than in 2001 (in early, rather than late, April). Similarly, monthly mean and maximum water temperatures were higher in 1982 than in 1983, the reference year for the mesotrophic phase (Fig. 1B).

Total zooplankton biomass in the warmer year was higher than that attained in the "normal" year during both the mesotrophic and the oligotrophic periods (Fig. 2A). However, this increase was driven by copepods and rotifers during the mesotrophic phase, whereas in the recent, oligotrophic period, it mainly resulted from 

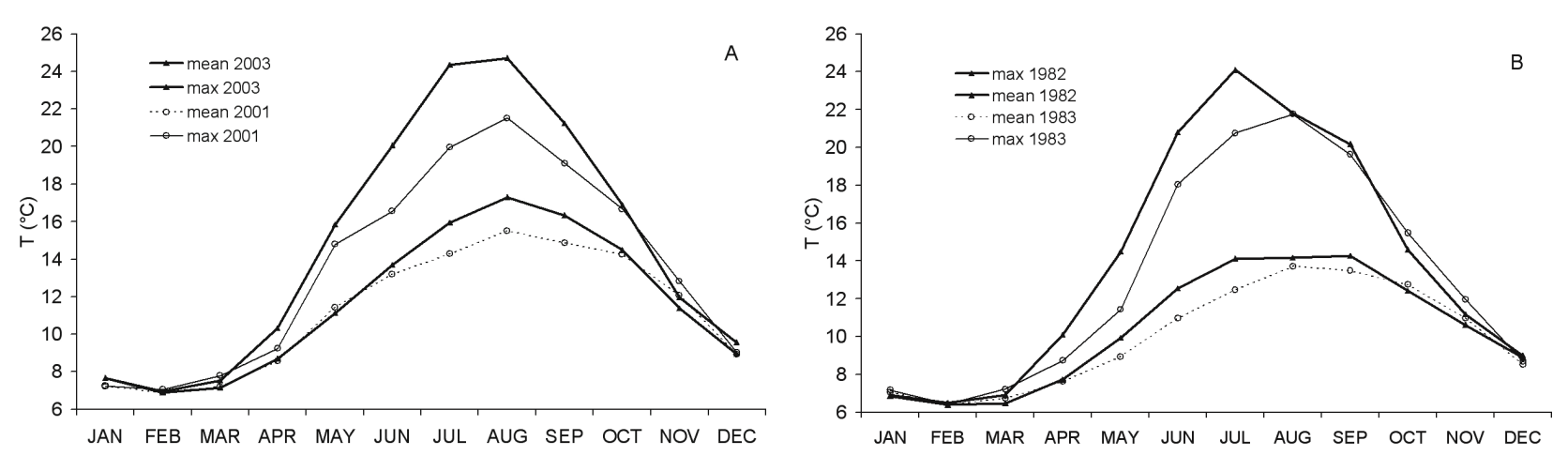

Fig. 1. Water temperatures in the upper $50 \mathrm{~m}$ of Lago Maggiore, comparison between a warm and a temperate year, A: during oligotrophy (2003/2001) and B: during mesotrophy (1982/1983).
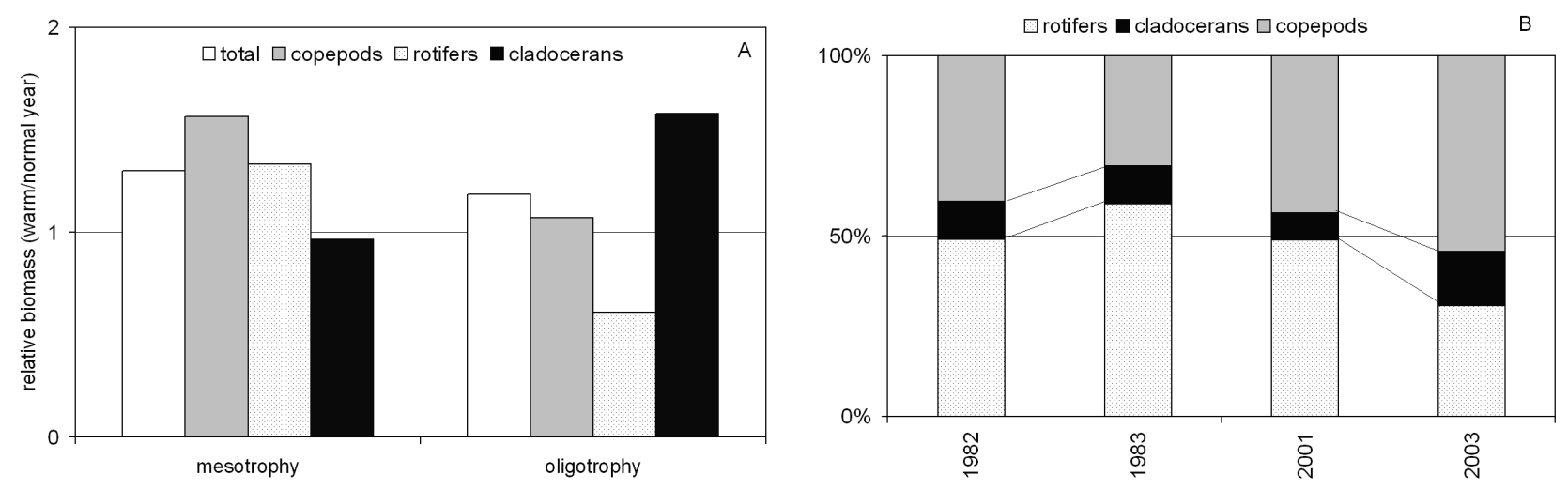

Fig. 2. Changes in zooplankton biomass recorded with warming; A: comparison between warm and temperate years during oligotrophy and mesotrophy; B: contribution (\%) of copepods, rotifers and cladocerans to the total zooplankton biomass attained in the four different years (for explanation see Tab. 1).

an increase in Cladocera, while the biomass of rotifers actually decreased. Colonial rotifers of the Conochilus unicornis-hippocrepis group were abundant during the initial phase of lake re-oligotrophication when Daphnia declined but were returning to more typical levels during this assessment (Manca et al. 2000).

The contribution of Cladocera to the mean annual population density of total zooplankton did not change in the warm year with respect to the normal one of the mesotrophic phase (Fig. 2B). The observed increase in population density and biomass was driven by the rotifers and the copepods, and the relative importance of rotifers was markedly higher. For the recent oligotrophic period, the relative contribution of Cladocera to total zooplankton population density was twice as great in the warm year as in the normal one. While the population density of Cladocera was only slightly higher in 1982 than in 1983, it was consistently greater in 2003 than in 2001, and attained a value comparable to that achieved in 1982, when the lake was mesotrophic (Fig. 3A). The increase was driven by Daphnia, which reached truly exceptional levels: both mean and peak densities were three times higher than in 2001. Further- more, 2003 densities were very similar to the density recorded in 1982, when Daphnia populations levels reached their historical maximum for the period of mesotrophic conditions (1978-1987; Fig. 3B; de Bernardi et al. 1988; Manca \& de Bernardi 1992).

Daphnia population densities in 2003 were statistically different from those observed in the period 19992002, but not from those observed in 1982, the warm year of the mesotrophic period (Tab. 2). Daphnia population densitities in 1982 did not differ from those observed in the adjacent four years of the same trophic phase (1983-1986), which were, however, statistically different from those observed during the more recent oligotrophic phase (1999-2002).

A comparison of the values of the egg ratio $(\mathrm{E} / \mathrm{Nad})$ before the numerical growth phase of 2001 and 2003 (in April: 3.5 with respect to 7) suggests that the Daphnia increase of 2003 was driven by a higher fecundity of the population observed over the entire spectrum of mothers' body-sizes (i.e., size-aspecific) Manca et al. (2008), attributable to enhanced food conditions. The increase in Daphnia population density was accompanied by an increase in water transparency (Secchi depth from 5 to 


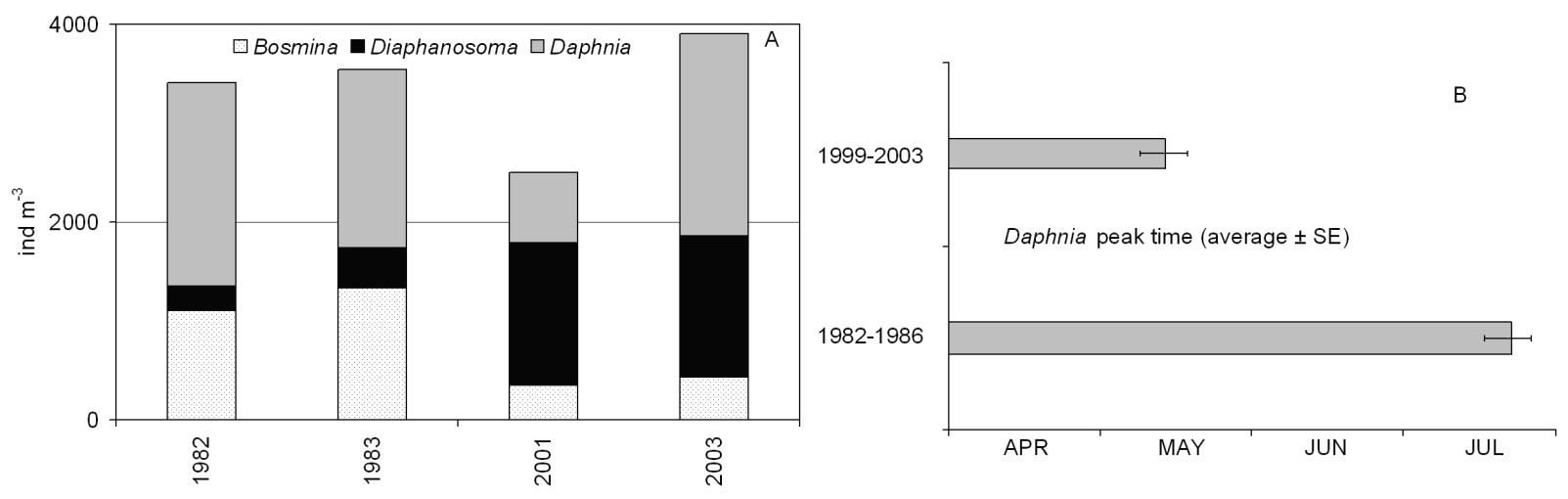

Fig. 3. Population densities (ind $\mathrm{m}^{-3}$ ) of Lago Maggiore's zooplanktonic cladocerans in warm and temperate years of the mesotrophic and oligotrophic phases; A: mean annual densities of Bosmina, Diaphanosoma and Daphnia; B: peak values and timing (horizontal bars referring to SE of the means ) of Daphnia.

$8.5 \mathrm{~m}$ ), suggesting a more effective control of phytoplankton growth and an increased efficiency of the grazing food chain.

Tab. 2. Pairwise comparison (LSD test) of Daphnia population densities in exceptionally warm and temperate years during oligotrophic and mesotrophic periods. $\mathrm{W}=$ warm; $\mathrm{T}=$ temperate; $\mathrm{O}=$ oligotrophy; $\mathrm{M}=$ mesotrophy.

\begin{tabular}{lcc}
\hline & $p$ & treatments \\
\hline 2003 vs 1982 & 0.7859 & WO/WM \\
$\mathbf{2 0 0 3}$ vs $\mathbf{1 9 9 9 - 2 0 0 2}$ & $\mathbf{0 . 0 0 2 6}$ & WO/TO \\
2003 vs $1983-86$ & 0.4320 & WO/TM \\
$\mathbf{1 9 8 2}$ vs $\mathbf{1 9 9 9 - 2 0 0 2}$ & $\mathbf{0 . 0 3 3 6}$ & WM/TO \\
1982 vs $1983-86$ & 0.4295 & WM/TM \\
$\mathbf{1 9 8 3 - 8 6}$ vs $\mathbf{1 9 9 9 - 2 0 0 2}$ & $\mathbf{0 . 0 1 7 8}$ & TM/TO \\
\hline
\end{tabular}

\section{DISCUSSION}

The proximate responses of Cladocera to warming, and particularly the increase in Daphnia population density to levels exceptional for the years following reoligotrophication of Lago Maggiore, seem to be driven by bottom-up mechanisms, as suggested by indirect indicators of food conditions. We may hypothesize that they were related to enhanced food availability, as warming may result in faster numerical growth of the small planktonic organisms that constitute high-quality food for herbivorous Cladocera, and particularly for Daphnia. This interpretation is consistent with the idea that the response of organisms to warming will likely depend on their developmental times, and furthermore, that reaction time will depend on the body size and therefore on the trophic role of the organism.

In addition, data on professional fishing (Tab. 1) suggest that the two years we used to assess the impact of warming during the mesotrophic period (early $80 \mathrm{~s}$ ) as compared to the oligotrophic period were fully comparable. This means that the effects of fish predation can be excluded, although there is evidence that vulnerability to predation can change at a stable fish stock, also as a result of changes in the physical environment (Manca et al. 2007a). However, the fact that the increase in egg ratio was size-aspecific supports the interpretation of a bottom-up control (Manca \& Marchitelli 2004). Being observed in April, we can also exclude a role of invertebrate predators, which, by removing smaller-sized individuals, can promote an increase in fecundity and stabilize the prey population thus preventing its extinction (de Bernardi 1974; Polishchuk 1995; Manca et al. 2008).

On an annual basis, the population density and biomass in the warm year of the recent oligotrophic period were comparable with those in the warm year of the mesotrophic phase. However, the actual Daphnia population's phenology has changed over the long-term: in 1983-1986 the population peak density was detected, with only slight variations, in mid-July, while in the most recent period (2000-2003) it occurred, again with very low variability, two months earlier (Fig. 3B). The change in phenology is consistent with a temperaturedriven pattern resulting from a direct effect of temperature on growth and developmental time (Hall \& Burns 2002), as well as from indirect effects related to changes in the lake thermal stratification regime (Manca et al. 2007a).

\section{CONCLUSIONS}

The results of our study suggest that in exceptionally warm years of the oligotrophic phase, mean annual zooplankton biomass reached high values, fully comparable with those recorded during the lake's mesotrophic period. However, in Lake Maggiore, the increase was driven by rotifers and copepods during the mesotrophic period, and by the Cladocera during the recent oligotrophic period.

The relative abundance of Daphnia within the Cladocera and its peak population density in the warm year of the oligotrophic period (2003) were comparable to levels recorded during the mesotrophic period. Indeed, Daphnia density was very close to the record level reached in 1982, thus supporting the hypothesis 
that warming may result in an eutrophication-like signal.

As suggested by the egg ratio (E/Nad), Daphnia density increase in the warm year of the oligotrophic phase resulted from enhanced food conditions. The increase in Daphnia is accompanied by an increase in water transparency - suggesting the enhancement of the top-down control of phytoplankton growth - and by a decrease in the colonial rotifer populations, which had increased along with the Daphnia decline (long-term data; Manca et al. 1994; Manca \& Sonvico 1996; Manca et al. 2000).

However, although 2003 showed zooplankton biomass and density levels that were generally similar to those observed during the mesotrophy, relevant differences are evident when the seasonal dynamics are compared. Whereas, in the past, the peak density of the Daphnia population was recorded with low variation around mid-July (de Bernardi 1974), in the most recent period, as a "long-term" consequence of climate warming and of an earlier onset of thermal stratification (Manca et al. 2007a), Daphnia population density peaks about 2 months earlier than in the past. This result suggests that changes in population phenology are probably of key importance for distinguishing responses related to warming versus eutrophication, and for investigating the mechanisms through which water temperature or nutrient enrichment can act on zooplankton populations.

However, in an aquatic environment like the large and deep Lago Maggiore, in which the efficiency of the pelagic food web is mainly controlled by top-down mechanisms (de Bernardi \& Jørgensen 1998; Manca et al. $2007 \mathrm{~b}$ ), we can expect that direct effects of water temperature increases (i.e., higher density levels due to faster growth rates of the populations) will be temporary and, in the long term, of minor importance relative to indirect effects mediated through the food chain (Manca et al. 2007a).

According to the European Environmental Agency, changes in phenology are crucial for understanding and predicting the impact of global warming on aquatic ecosystems. While the short-term response will be related to a direct impact on aquatic ecosystems, the long-term impact (i.e., stable changes) will be related to indirect (i.e., ecosystem-mediated) mechanisms.

We showed that data on the zooplankton of lakes which have undergone both eutrophication and reoligotrophication are crucial for testing exceptional patterns and short-term responses to global warming. However, the establishment of new scenarios and the long-term consequences of climate warming will almost certainly be the result of gradual transitions and ecosystem-mediated patterns.

\section{ACKNOWLEDGMENTS}

We are very grateful to S. Levine, J. Vijverberg and R. Caroni for critical comments and the revision of the manuscript. We thank Elisa Peters for the language revision of an earlier version of the manuscript.

\section{REFERENCES}

de Bernardi, R. 1974. The dynamics of a population of Daphnia hyalina Leydig in Lago Maggiore, Northern Italy. Mem. Ist. ital. Idrobiol., 31: 221-243.

de Bernardi, R., G. Giussani, M. Manca \& D. Ruggiu. 1988. Long-term dynamics of plankton communities in Lago Maggiore (Northern Italy). Verh. int. Ver. Limnol., 23: 729-733.

de Bernardi, R., G. Giussani, M. Manca \& D. Ruggiu. 1990. Trophic status and the pelagic system in Lago Maggiore. Hydrobiologia, 191: 1-8.

de Bernardi, R. 1984. Methods for the estimation of zooplankton abundance. In: Downing J.A. \& F.H. Rigler (Eds), A manual of methods for the assesmen of secondary productivity in fresh water. Blackwell Scientific Publications: 59- 86.

de Bernardi, R. \& S. Jørgensen. 1998. Exergy content in the pelagic food chain of Lago Maggiore. Lakes \& Reservoirs: Research and Management, 3: 135-138.

De Stasio, jr.B.T., D.K. Hill, J.M. Keinhans, N.P. Nibbelink \& J.J. Magnusson. 1996. Potential effects of Global Climate Change on Small North-Temperate Lakes: Physics, Fish and Plankton. Limnol. Oceanogr., 41(5): 1136-1149.

Edmondson, T.W. 1993. Experiments and quasi-experiments in limnology. Bull. Mar. Sci., 53: 11.

Hall, C.J. \& C.W. Burns. 2002. Mortality and growth responses of Daphnia carinata to increases in temperature and salinity. Freshwat. Biol.. 47: 451-458.

Lampert, W. 1988. The relative importance of food limitation and predation in the seasonal cycle of two Daphnia species. Int. Ver. Theor. Angew. Limnol. Verh., 23: 713-718.

McCauley, E. 1984. The estimation of abundance and biomass of zooplankton in samples. In: Dowing J.A. \& F.H. Rigler (Eds), A manual on methods for the assessment of secondary productivity in fresh waters. Blackewell Scientific Publications: 228-265.

Manca, M. \& R. de Bernardi. 1987. Feeding and energy budget estimations in Daphnia obtusa. Hydrobiologia, 145: 269-274.

Manca, M., A. Calderoni \& R. Mosello. 1991. Limnological research in Lago Maggiore: studies on hydrochemistry and plankton. Mem. Ist. ital. Idrobiol., 50: 171-200.

Manca, M \& R. de Bernardi. 1992. Indagini sullo zooplancton. In: CNR Istituto Italiano di Idrobiologia (Ed.), Ricerche sull'evoluzione del Lago Maggiore. Aspetti Limnologici. Programma quinquennale 1983-1987 (Campagna 1992) e rapporto quinquennale 1988-1992. Commissione Internazionale per la Protezione delle Acque Italo Svizzere: 68-78.

Manca, M., T. Spagnuolo \& P. Comoli. 1994. Variation in carbon and nitrogen content with body length of Daphnia hyalina-galeata s.l. from laboratory and field observations. J. Plankton Res., 16: 1303-1341.

Manca, M. \& D. Sonvico. 1996. Seasonal variations in population density and size structure of Conochilus in Lago Maggiore: a biannual study. Mem. Ist. ital. Idrobiol., 54: 97-108.

Manca, M. \& D. Ruggiu. 1998. Consequences of pelagic food web changes during a long-term lake oligotrophication process. Limnol. Oceanogr., 43: 1368-1373.

Manca, M. \& P. Comoli. 2000. Biomass estimates of freshwater zooplankton from length-carbon regression equations. J. Limnol., 59(1): 15-18.

Manca, M., C. Ramoni \& P. Comoli. 2000. The decline of Daphnia hyalina-galeata in Lago Maggiore: a comparison of the population dynamics before and after oligotrophication. Aquat. Sci., 62: 142-153. 
Manca, M. \& A. Marchitelli. 2004. Dinamica stagionale del popolamento zooplanctonico nel corso del 2003. In: CNR.-Istituto per lo Studio degli Ecosistemi (Ed.), Ricerche sull'evoluzione del Lago Maggiore. Aspetti limnologici. Programma quinquennale 2003-2007. Campagna 2003. Commissione Internazionale per la protezione delle acque italo-svizzere: 61-67.

Manca, M., M. Portogallo, \& M. E. Brown. 2007a. Shifts in phenology of Bythotrephes longimanus and its modern success in Lake Maggiore as a result of changes in climate and trophy. J. Plankton Res., 29(6): 515-525.

Manca, M., J. Vijverberg, L. V. Polishchuk \& D. A. Voronov. 2008. Daphnia body size and population dynamics under predation by invertebrate and fish predators in Lago Maggiore: an approach based on contribution analysis. $J$. Limnol., 67(1): 15-21.

Received: March 2008

Accepted: June 2008
Manca, M., B. Torretta, P. Comoli, S. Amsinck \& E. Jeppesen. 2007b. Major changes in trophic dynamics in large, deep sub-alpine Lake Maggiore from 1940s to 2002: A high resolution comparative palaeo-neolimnological study. Freshwat. Biol., 52(11): 2256-2269.

Persaud, A.D. \& C.E. Williamson. 2005. Ultraviolet and temperature effects on planktonic rotifer and crustaceans in northern temperate lakes. Freshwat. Biol., 50: 467-476.

Polishchuk, L.V. 1995. Direct positive effect of invertebrate predators on birth rate in Daphnia studied with a new method of birth rate analysis. Limnol. Oceanogr., 40: 483489.

Schindler, D.W. 2001. The cumulative effects of climate warming and other human stresses on Canadian freshwaters in the new millennium. Can. J. Fish. aquat. Sci., 58: 18-29. 